\title{
Capitão: a aplicação da Indirect Rule nos Povos Kaiowá e Guarani
}

\section{Captain: the application of Indirect Rule in the Kaiowá and Guarani People}

\author{
Marco Antonio Delfino de Almeida ${ }^{1}$ \\ Thiago Leandro Vieira Cavalcante ${ }^{1}$
}

DOI: http://dx.doi.org/10.20435/tellus.v19i39.572

Resumo: O artigo apresenta o conceito de indirect rule ou governo indireto formulado para aplicação nas colônias africanas durante o colonialismo do século XIX e discute sua aplicação pelo Estado colonial brasileiro por meio do Serviço de Proteção ao Índio no Brasil (SPI). Tal aplicação se deu por meio da imposição de um novo modelo de liderança nas reservas indígenas criadas pelo SPI. Esse modelo se materializou na figura do capitão a quem, na condição de indígena, cabia impor aos demais as diretrizes emanadas do SPI, configurandose então uma forma de governo indireto, também característica do colonialismo interno. A autoridade do capitão se sobrepôs às lideranças tradicionais tornando foco perene de tensões e conflitos. Observa-se que mesmo após a Constituição Federal de 1988 esse modelo de liderança permanece, demonstrando que de alguma forma a capitania foi apropriada pelos indígenas.

Palavras-chave: capitania; colonialismo interno; Serviço de Proteção ao Índio; governo indireto.

\begin{abstract}
The article presents the concept of indirect rule formulated for application in the African colonies during nineteenth century colonialism and discusses its application by the Brazilian colonial state through the Serviço de Proteção ao Índio (SPI) (Indian Protection Service) in Brazil. This was done through the imposition of a new model of leadership in indigenous reserves created by the SPI. This model materialized in the figure of the captain, whom, as an indigenous person, it was necessary to impose guidelines emanated from the SPI to the others, an indirect form of government was constitute, also characteristic of internal colonialism. The captain's authority overcame the traditional leadership by making a recurrent focus of tensions and conflicts. It is observed that even after the Federal Constitution of 1988 this model of leadership persist, demonstrating that in some way the captaincy was appropriated by the Indians.
\end{abstract}

${ }_{1}$ Universidade Federal da Grande Dourados, Dourados, Mato Grosso do Sul, Brasil. 
Keywords: captaincy; internal colonialism; Indian Protection Service; indirect government.

\section{INTRODUÇÃO}

Encontrei hoje em ruas, separadamente, dois amigos meus que se haviam zangado um com $\mathrm{O}$ outro.Cada um me contou a narrativa de por que se haviam zangado. Cada um me disse a verdade. Cada um me contou as suas razões. Ambos tinham razão. Não era que um via uma coisa e outro outra, ou que um via um lado das coisas e outro um outro lado diferente. Não: cada um via as coisas exatamente como se haviam passado, cada um as via com um critério idêntico ao do outro, mas cada um via uma coisa diferente, e cada um, portanto, tinha razão. Fiquei confuso desta dupla existência da verdade. (PESSOA, 1986, p. 47).

Com referência aos índios estarem devassando o mandiocal, tendo como cabeça o índio Capitão da Aldeia, e que pretendia fazer uma mudança de capitão e polícia, esta Chefia aprova, visto que vem de muito se adotando essa medida, de ser o capitão dos índios escolhido pelos Encarregados dos Postos, que, depois deste escolhido, serão escolhidos, também, os auxiliares de Polícia Indígena, que deve compor de 1(sic) tenente, 1(sic) sargento, 2(sic) cabos, e os soldados quantos sejam necessários, de acordo com o numero de índios aldeados. Esta escolha será entre o Enc, do Posto e o Capitão, e enviado a esta IR, para expedição das Portarias de Capitão, tenente e sargento. A ordem e a disciplina obedecerá os deveres hierárquicos, devendo, portanto ser executado o plano, se ainda não foi. (BRASIL, 1954).

O contraste entre a história oficial sintetizada no dístico "Morrer se preciso for... matar, nunca!" e as práticas colonialistas do Serviço de Proteção ao Índio (SPI) representam excelente demonstração fática das palavras de Fernando Pessoa. "Serviço de Proteção ao Índio" ou efetivamente, "Serviço de Dominação do Índio"? A negação do jugo colonial sobre as populações indígenas pode representar mais uma faceta da nossa "aversão" ou "negação" da nossa imagem ao espelho. Como "Democracia Racial" e Racismo representam as duas faces de Janus na sociedade brasileira: a primeira propalada pelas elites, a segunda esculpida pelas ruas e pelos índices sociais que confirmam a exclusão. O tema é vasto, especialmente pela utilização da tutela ou do poder tutelar como sinônimos eufemísticos do processo de dominação colonial (LIMA, 1995; 1987; OLIVEIRA, 1986). 
O presente trabalho, de forma abreviada, abordará o tema sob a perspectiva da motivação histórica do processo de "proteção" e da consequente utilização de estruturas coloniais para a obtenção dos desideratos econômicos almejados, especificamente, a utilização do denominado indirect rule ou governo indireto, por meio do processo de seleção e da imposição de lideranças não tradicionais na forma de "capitães" nas comunidades Kaiowá e Guarani do atual Mato Grosso do Sul.

O texto propõe uma relação entre as formas coloniais de dominação presentes no colonialismo clássico, especialmente observado na África no século XIX, e aquelas que seguem presentes na sociedade brasileira, regida pela presença da colonialidade do poder que se estende para além do término da colonização clássica na América.

\section{INDIRECT RULE}

A expressão "governo indireto" é uma tradução do conceito expresso em inglês, indirect rule, que foi utilizado originalmente para denominar o sistema político-administrativo descentralizado praticado nas colônias africanas controladas pelo Reino Unido (particularmente no Quênia e na Nigéria) entre o final do século XIX e as primeiras décadas do século XX. Está baseado no estabelecimento de "intermediários nativos" (uma espécie de "administrador nativo") situados entre a população local e os administradores britânicos. Política semelhante foi utilizada, na relação com os povos indígenas, pelos Estados Unidos entre os anos 1930 e 1940 (BLANCHETTE, 2010). O indirect rule foi um momento geral que exprimiu a necessidade dos colonizadores redefinirem os seus postulados assimilacionistas (LECLERC, 1973), e que, no caso da África britânica, tomou a forma do que Mahmood Mamdani (1996) chamou de "despotismo descentralizado".

A menção ao termo indirect rule é associada ao seu suposto criador. O militar e administrador colonial britânico, Frederick Lugard (1929, p. 199) com o consequente estabelecimento do governo colonial por intermédio dos representantes das populações nativas e suas próprias instituições. Malinowski (1945, p. 138) aponta que o sistema teria como principais vantagens o fato de ser barato, prático, de fácil implementação devido ao mínimo de fricção e insatisfação, uma vez que contaria com o consentimento da maioria dos que seriam governados. 
Aspecto interessante, sobre o ponto de vista ético e histórico, é a utilização dos antropólogos como meio preferencial de identificação da forma de estruturação das sociedades a serem colonizadas com a associada identificação das lideranças "tradicionais".

Esta utilização, cuja abordagem mais detalhada demandaria um trabalho específico, é apresentada no trabalho de Malinowski (1945, p. 138-9) ao detalhar que seria um truísmo antropológico a afirmação de que a autoridade é melhor exercida pelas lideranças seculares, que possuem prestígio perante a comunidade, que possuem funções religiosas e a quem são atribuídos poderes mágicos. Caberia ao antropólogo a correta identificação desta liderança e a consequente operacionalização da indirect rule.

Malinowski (1945, p. 147) igualmente aponta as dificuldades na sua implementação, caso não ocorra na aplicação descolada da realidade fática. É fundamental que ocorra a compreensão, por parte dos nativos dos objetivos coloniais, e a recíproca compreensão das "limitações" das lideranças locais. Em sua visão, o objetivo fundamental seria a instituição de uma liderança local devotada, dependente, controlada, mas poderosa, rica e satisfeita. O processo de fortalecimento econômico da liderança deve ser provido pelas estruturas coloniais para que ocorra o custeio da "estrutura administrativa nativa", recompensa de seguidores e fartura de recursos a serem divididos.

Barnes (1960, p. 140) discorda da atribuição da paternidade do termo à Lugard. Sustenta que a instituição é milenar, remontaria aos romanos e que os princípios da técnica já teriam sido citados em um memorando do administrador colonial britânico em Uganda, o capitão Thruston, em 1897. Na antiguidade oriental também é possível encontrar formas de dominação imperialista com formas de governo indireto, caso do Império Persa em relação aos Hebreus, por exemplo.

Ponto relevante trazido a debate por Barnes (1960, p. 143) refere-se à implementação do sistema do indirect rule em sociedades que não possuem um sistema de liderança centralizada, mas, sim de lideranças "grupais" como as existentes nas famílias extensas dos Kaiowá e Guarani ou os grupos classificados como vicinais (OLIVEIRA FILHO, 1986, p. 386-7). Nestes casos ocorreria a clara possibilidade de abandono dos mecanismos consensuais de resolução de conflitos com a consequente utilização intensiva de mecanismos coercitivos e da violência. A 
ausência de vinculação a uma autoridade preexistente (seja pela não identificação da efetiva liderança em uma estrutura centralizada, seja pela imposição de uma estrutura descentralizada) acarreta a necessidade de demonstração ostensiva do dever de obediência e das consequências do descumprimento. Neste cenário, há clara possibilidade de estabelecimento de "tiranias" com emprego frequente de violência.

Mamdani (1996, p. 18) pontua que os mecanismos de controle direto e indireto (direct e indirect rule) são mecanismos complementares do sistema colonial. O sistema de controle direto vige nas áreas urbanas e se caracteriza pela exclusão discriminatória dos povos originários do acesso à plenitude dos direitos civis. Eufemisticamente, o que se buscaria não é uma segregação racial, mas uma separação entre "civilizados" e "não civilizados". As citações abaixo transcritas expressam a teoria formulada.

Por outro lado, uma vez que este sentimento existe, deve-se, em minha opinião, tornar-se bastante claro que o que se pretende é uma segregação dos padrões sociais, e não uma segregação de raças. O cavalheiro indiano ou africano que adote o padrão mais elevado de civilização e deseje participar dessa imunidade à infecção proporcionada pela segregação, deve ser tão livre e bem-vindo a viver na área civilizada como o europeu, desde que, claro, ele não traga consigo um séquito de seguidores. O camponês nativo freqüentemente compartilha sua cabana com sua cabra, ou ovelhas, ou aves. Ele gosta de usar tambores e dançar à noite, o que priva o europeu do sono. [...]. 'Para essas pessoas, as regras sanitárias são necessárias, mas odiosas. Elas não têm o desejo de abolir a segregação'. (LUGARD, 1929, p. 150, tradução nossa)².

A fundação desse Posto nas terras reservadas para os índios Caiuás, junto ao Patrimônio de Dourados demonstrou bem cedo, que muito se pode obter, da disciplina e regeneração dos costumes do índio, com uma assistencia a elle feita, em a qual se procure conduzil-o ao trabalho e bom comportamento.

2 On the other hand, since this feeling exists, it should in my opinion be made abundantly clear that what is aimed at is a segregation of social standards, and not a segregation of races. The Indian or African gentleman who adopts the higher standard of civilisation and desires to partake in such immunity from infection as segregation may convey, should be as free and welcome to live in the civilised reservation as the European, provided, of course, that he does not bring with him a concourse of followers. The native peasant often shares his hut with his goat, or sheep, or fowls. He loves to drum and dance at night, which deprives the European of sleep. [...]." For these people sanitaryrules are necessary but hateful. They have no desire to abolish segregation. 


\section{Antes da fundação do "Posto Francisco Horta" era comum o ver-se indios embriagados perambulando pelas ruas do povoado, principalmente aos domingos.}

Pouco mais de anno faz que aquelle Posto foi installado e, entretanto, já se não vê a reprodução de facto tao lamentável. (BARBOSA, 1927 apud MONTEIRO, 2003).

É notável a similaridade do pensamento colonial, o mesmo objetivo segregacionista é alcançado tanto pelo colonialismo clássico quanto pelo colonialismo interno vivenciado no Brasil, seja pela via "sanitária", seja pela via da "assistência" ou "proteção".

Por fim, a exposição da figura do denominado chefe. O complexo de poderes a ele associados é comum aos sistemas coloniais franceses, britânicos e, obviamente, à implementação colonial brasileira no indigenismo. Há, na prática, a fusão dos poderes administrativos, legislativos, judiciais em uma única entidade. Mamdani (1996, p. 23) compara o chefe colonial a um "punho cerrado localizado na intersecção entre a zona de mercado e a zona do não mercado". Era o instrumento de implementação de uma série de coerções necessárias ao sistema colonial: trabalho forçado, colheitas forçadas, contribuições forçadas e remoções forçadas, tanto lá como aqui.

\section{GÊNESE DA DOMINAÇÃO COLONIAL NO BRASIL}

A fundamentação teórica e econômica para o processo de dominação colonial dos povos originários, na fase Republicana, pode ser vislumbrada no trabalho do General Couto Magalhães. O trabalho de Couto Magalhães foi elaborado, a pedido do Imperador Pedro II, para figurar na biblioteca americana da Exposição Universal de Filadélfia em 1876, comemorativa do Centenário da Independência Americana. A Exposição, que ocorreu entre os dias dez de maio e dez de novembro de 1876, contou com a presença do Imperador Dom Pedro II em sua abertura. Os assuntos debatidos no livro apresentam um relevante tema à época. Em 25 de junho de 1876 aconteceu a Batalha de Little Big Horn, entre unidades do Exército Americano e indígenas do povo Lakota. Paralelamente, havia a intervenção militar chilena no território Mapuche, denominada "Pacificação da Araucania (1862-1883) e igualmente a intervenção militar argentina em face das comunidades indígenas 
Mapuche, Tehuelche e Ranquel, denominada de "Conquista do Deserto". Neste contexto, o debate centrava-se no destino das comunidades indígenas: a) o extermínio ou b) o aproveitamento econômico. A solução gestada por Couto Magalhães (1876, p. 18-20) aponta para "O selvagem como elemento econômico".

O fato da existência desse milhão de braços, ocupando e dominando a maior parte do território do Brasil, podendo irromper para qualquer lado contra as populações cristãs, é um embaraço para os progressos do povoamento do interior e é um perigo que crescerá na proporção em que eles forem ficando mais apertados: a questão, pois, não versa só sobre a utilidade que podemos tirar do selvagem; versa também sobre os perigos e despesas que faremos, se não cuidarmos agora de amansá-los.

Não estará longe o dia em que seremos forçados, como a República Argentina, o Chile, os Estados Unidos, a manter verdadeiros corpos de exército para conter nossos selvagens, se abandonarmos essa questão ao seu natural desenvolvimento.

Em janeiro deste ano ainda os jornais deram notícia dos estragos que eles fizeram na República Argentina, estragos que montaram, alem da perda de vidas, a mais de mil e quatrocentos contos de nossa moeda!

$[\ldots]$

Estes prejuízos, as despesas que serão necessárias com movimento de forças, as perturbações sociais que provirão de conflitos sanguinolentos no interior, mostram que quaisquer despesas que fizermos agora para assimilar os selvagens na nossa sociedade serão incomparavelmente menores do que as que teremos de fazer se, por não prestarmos atenção ao assunto, formos forçados a exterminá-los. (MAGALHÃES, 1876, p. 1820 , grifos nossos).

Prossegue Couto Magalhães com sua visão claramente utilitarista,

Portanto, nem pelo número nem pela posição, os perigos a que as populações cristãs ficarão expostas, desde que os selvagens se virem mais apertados, não são inferiores, pelo contrário são maiores do que aqueles a que atualmente está exposta a República Argentina; e se ali ainda este ano os selvagens, que são dez vezes menos numerosos do que os nossos, puderam destruir, em uma só incursão, valores equivalentes a mil quatrocentos e muitos contos, que esforços não devemos nós empregar para fugirmos de idêntica situação, com selvagens mais numerosos e com um país de muito mais difícil comunicação, sobretudo quando este selvagem nos pode ser tão útil? (MAGALHÃES, 1876, p. 22, grifos nossos). 
Neste sentido caminha igualmente o pensamento rondoniano conforme podemos constatar pela leitura dos Relatórios do Ministério de Agricultura Indústria e Comércio de 1913 e 1917:

Não resta dúvida de que o governo, do mesmo passo que protege, ampara e salva o índio brasileiro, promove e assegura os meios indispensáveis à conquista de grande parte do interior do país, até então vedado tanto aos nacionais como aos estrangeiros. Era, aliás, esta, uma iniludível obrigação de nossa política administrativa, que precisava por termo à falta de segurança oferecida aos visitantes de nossas matas e sertões, que até agora viam nas populações selvagens do Brasil inimigos muito mais temerosos do que as suas feras. (BRASIL, 1913 apud LIMA, 1995).

O Serviço de Proteção aos Índios e Localização de Trabalhadores Nacionais (tendo- Ihe sido acrescida esta última parte, ao momento da criação, em razão do engrenamento do problema indígena com o do trabalhador sertanejo, pela seriação do selvagem, do pacificado e do caboclo já fundido na população) nasceu, como V.Exa. sabe, do êxito dos processos praticados pelo então Tenente-Coronel Cândido Rondon, para pacificação das tribos selvícolas encontradas em seu caminho, ao fazer a travessia do Brasil central estendendo a linha telegráfica de Mato Grosso ao Amazonas, processos já empregados pelo saudoso naturalista Dr. João Barbosa Rodrigues na pacificação dos Crichanás, em 1874; e da demonstração de que se poderia conseguir com os mesmos efeitos ein todas as regiões do Brasil onde ainda se encontrassem, como infelizmente se encontram, indígenas selvagens, isto é - brasileiros reduzidos a condição de brutos, inúteis a si e à coletividade e, o que é mais, entravando, em mais de um ponto, o aproveitamento da terra e das forças naturais, ele inclusive, e sendo exterminados barbaramente,como feras por pseudocivilizados sem consciência e sem alma, a quem o índio involuntariamente prejudicava na tranqüilidade e na cobiça... . (BRASIL, 1917, p. 1, grifos nossos).

É possível afirmar, à luz dos documentos apresentados, que a Proteção dos índios não representava um fim, mas um meio para obtenção do efeito econômico desejado: a utilização da mão-de-obra indígena no processo de colonização do interior do Brasil. Em um cenário de carência de recursos tecnológicos para exploração das áreas (como, por exemplo, a extração da erva mate e derrubada de matas para implantação de pastagens). A localização topográfica do SPI na estrutura burocrática federal (vinculada ao Ministério da Agricultura, durante a maior parte do período de sua existência) não permite uma conclusão em outra direção.

Como exposto por Couto Magalhães. 


\section{Povoar o Brasil quer dizer:}

10) Importar colonos da Europa para cultivar as terras já desbravadas nos centros, ou próximos aos centros povoados.

2ㅇ) Aproveitar para a população nacional as terras ainda virgens, onde o selvagem é um obstáculo; estas terras representam quase dois terços do território do Império. Tornar produtiva uma população, hoje improdutiva, é, pelo menos, tão importante como trazer novos braços.

3ㅇ) Utilizar cerca de um milhão de selvagens que possuímos, os quais são os que melhores serviços podem prestar nessas duas terças partes do nosso território, porque as indústrias extrativas, únicas possíveis nessas regiões (enquanto não houver estradas), só têm sido e só podem ser exploradas pelo selvagem. (MAGALHÃES, 1876, p. 12, grifos nossos).

No Brasil, esta opção foi claramente exposta na legislação, conforme podemos verificar pela leitura do Decreto-Lei n. 1.736/1939 que subordinou o SPI ao Ministério da Agricultura. O decreto traz mais luzes ao efetivo objetivo do "Grande Cerco de Paz" rondoniano: tornar os índios "úteis", produtivos mediante o auxílio às populações civilizadas destes "[...] homens aclimados ao solo e habituados à vida semi-bárbara [...]" (BARBOSA, 1927 apud MONTEIRO, 2003).

[...] que o problema da proteção aos índios se acha intimamente ligado à questão de colonização, pois se trata, no ponto de vista material, de orientar e interessar os indígenas no cultivo do solo, para que se tornem úteis ao país e possam colaborar com as populações civilizadas que se dedicam às atividades agrícolas. (BRASIL, 1939, grifos nossos).

É importante ressaltar que na formação da sociedade brasileira, especialmente na relação entre o Estado e os povos indígenas, o colonialismo clássico teve termo em 1822, no entanto, a independência aqui realizada não teve caráter nacional. Principalmente os indígenas, continuaram sendo tratados como não participantes da nova nação que se pretendia construir.

Aníbal Quijano postula que os Estados-nacionais constituídos nos processos de independência no continente americano só chegaram a essa condição porque democratizaram, ainda que minimamente, o poder ou eliminaram fisicamente os diferentes. Pois, só há condições de se pensar a nacionalidade se houver certo grau de homogeneização de interesses. Dentre outros casos, no Brasil essa homogeneização não foi alcança no século XIX, tampouco no Brasil contemporâneo. Temos, portanto, um Estado independente, mas uma sociedade colonial. (QUIJANO, 2005). 
Com isso apesar do término do colonialismo formal, persistem ideias e práticas colonialistas levadas a cabo pelas elites políticas e econômicas do país, muitas vezes atendendo a interesses do capitalismo global. Essa continuidade de atitudes colonialistas pode ser chamada de colonialidade, ela segue como padrão de poder no Brasil.

A colonialidade proporciona ambiente perfeito para o colonialismo interno, que opera nos campos político, econômico, social e cultural. Consiste na dominação e colonização de minorias por elites do próprio Estado em que o processo ocorre (CASANOVA, 2006). Este padrão de dominação pode ser observado na política indigenista brasileira desde o século XIX e a aplicação do governo indireto é um de seus elementos característicos.

\section{INDIRECT RULE: O CASO DOS KAIOWÁ E GUARANI}

O processo de interferência na escolha de lideranças para as comunidades Kaiowá e Guarani de forma incipiente pode ser reportado ao final do século XIX, conforme pode ser deduzido do seguinte trecho da obra de Nimuendaju.

Antigamente os Guarani não reconheciam outro lider que o paje-principal. Mas, quando passaram a se relacionar com as autoridades brasileiras, estas - 'que jamais haviam levado em consideração os costumes e necessidades destes bugres' - nomearam principais todos aqueles que prometiam usar essa autoridade da melhor forma possível em favor dos que os nomearam. Qualquer delegadozinho das localidades vizinhas julgava-se no direito de influir de maneira civilizada sobre os 'bugres', nomeando ou destituindo chefes. As coisas pioravam, no entanto, quando alguns do bando conseguiam fazer uma viagem ate o presidente do estado ou mesmo da federação.(...). Àqueles pretendentes, contudo, o Governo conferia uniforme e patente de capitão, presenteando-os generosamente; tampouco faltavam recomendacões de manter a autoridade conferida perante os companheiros de tribo. Pode-se imaginar as conseqüências: uma parte do bando se mantem fiel a seu lider tradicional e declara hostilidade aberta ao pretendente; uma outra submete-se a ele por medo ao Governo[...]. (NIMUENDAJU, [1914] 1987, p. 75)

No início do século XX, após a criação do SPI, o processo de implantação da Indirect Rule nas comunidades Kaiowá e Guarani passou a ocorrer de forma burocratizada com a criação das reservas indígenas e consequente designação 
do capitão pelos chefes de Postos Indígenas ${ }^{3}$. Ressalte-se que a instituição do capitão subverteu a lógica sociopolítica tradicional desses grupos, uma vez que a imposição da força e a escolha externa substituíram um poder tradicionalmente descentralizado.

O poder das lideranças tradicionais se fundamentava em três elementos complementares: "[...] sua capacidade de falar, convencer e construir consensos internos (sua fala só tinha força enquanto manifestação deste consenso construído), tamanho de sua família extensa (parentes) e sua generosidade" (BRAND, 2001, p. 71). Referindo-se ao período colonial, Susnik (1979-1980) aponta para a existência de lideranças tradicionais tanto no âmbito das famílias extensas as te'ýi, cujos líderes eram os tuvicha, quanto no tekoha ${ }^{4}$, em que os líderes tinham maior prestígio e influência, sendo chamados de tuvicha ruvicha - equivalente a líder do tekoha. Percebe-se que as lideranças tradicionais eram reconhecidas fundamentalmente por seus laços de parentesco e pela capacidade de construir consensos de forma pacífica, por isso a boa desenvoltura fala era e é tão importante.

Pensando na configuração contemporânea, Alexandra Barbosa da Silva afirma que:

[...] é importante se ressaltar que a unidade sociológica fundamental entre esses grupos é a família extensa (isto é, de pelo menos três gerações, encabeçadas pelo tamõi e a jari, incluindo os filhos casados e seus cônjuges), cujo chefe é soberano nas decisões que concernem a este grupo. As decisões em escala comunitária (isto é, envolvendo mais de uma família) são definidas através de um consenso, alcançado em reuniões amplas (as aty guasu). Nestes termos, a bibliografia pertinente informa que tradicionalmente os líderes políticos (mburuvicha) eram definidos em face da necessidade de se enfrentar uma situação específica - caso das incursões guerreiras, por exemplo; passado este momento, desfazia-se a precisão de uma liderança. A autoridade a suscitar respeito perene concretizava-se (e se concretiza) na figura dos/das xamãs (respectivamente, ñanderu e ñandesy). (SILVA, 2007, p. 54).

3 Unidade descentralizada na estrutura organizacional do SPI, responsável pela relação direta com os indígenas residentes em Reservas Indígenas.

4 A definição do conceito de tekoha é tema de caloroso debate no campo da etnologia e da história indígena (ver: CAVALCANTE, 2013. p. 75-84). Em síntese, consideramo-la como uma categoria que expressa um dos níveis da organização social kaiowá e guarani que engloba algumas famílias extensas unidas por forte aliança política e religiosa. Além disso, o termo é utilizado para se referir ao espaço territorial onde tais relações sociais se desenvolvem no plano histórico. 
Atualmente, a liderança tradicional também é denominada como "cacique", conforme expõe o indígena Gonçalves, citado por Brand (2001, p. 71): “o cacique mesmo que mandava ali [...]. Naquela época não existia também esse chefe de posto, não existia o lugar, o lugar do capitão, era o cacique mesmo".

A criação da figura do capitão nas reservas indígenas do atual Mato Grosso do Sul remonta aos primeiros anos de atividade do Serviço de Proteção Indígena (SPI), órgão indigenista oficial na época, criado em 1910. No caso da Reserva de Caarapó, por exemplo, o primeiro capitão foi nomeado em 1920 (BRAND, 2001). O papel desse personagem está potencialmente carregado de conflitos e ambivalências, pois para se manter no poder ele tem de atender a pressões e a demandas vindas simultaneamente de duas direções: dos seus parentes e da comunidade indígena de abrangência da "sua administração" e da administração estatal, que exerce por meio dele o que vem a ser chamado na antropologia da política de "governo indireto".

A substituição da liderança tradicional pela estrutura colonial era efetivada a partir da discricionariedade de escolha por parte do representante do SPI, sem qualquer respeito aos processos próprios de organização. Ponto interessante é que o processo de seleção não obedecia aos critérios antropológicos relatados por Malinowski com a consequente exacerbação dos conflitos internos e a seguida erupção da violência, semelhante ao exposto por Barnes (1960). É o que podemos observar da seguinte transcrição ao responder a crítica apresentada pelo jornal "O Democrata", periódico que circulava na cidade de Campo Grande sobre o processo de seleção do capitão:

Em 22 de novembro de 1955.

Ao Sr. Encarregado do P.I. Francisco Horta

(...)

Com referência ao artigo publicado no Jornal "O Democrata" esta chefia não tomou conhecimento por ser sem fundamento e descabido, por isso nada vos mandou dizer.

A eleição entre os indios para escolherem seus chefes, é um caso rotineiro e da competência dos Agentes Encarregados dos Postos. Todavia observa-se que tal medida, bem intencionada como é, traz alguns inconvenientes, que é de ensinar política entre os índios, e nesse Posto com o agravante da infiltração comunista, que só trará encomodo (sic) e aborrecimentos, no 
entanto, a autoridade do Posto é o Encarregado do mesmo, que agirá como julgar para resolver os problemas da sua administração, e só as autoridades do Serviço compete intervir e não correspondente de Jornal fazer censura, de atos relacionados com indios.

Referente a chefia dos indios, si (sic) bem que os nossos Regimentos e Regulamentos não tratem dessa parte, porem, o que melhor resultado tem dado é o Encarregado do Posto que deverá observar qual o indio mais respeitado ou respeitável dentre os demais, e designar para chefe dos mesmos, e manda ele escolher seus auxiliares: um para substituto e mais uns 2 ou 3 que feito assim comunica a Chefia e esta expedirá Portarias dessas designações, ficando, assim organizada a Policia Indigena do Posto, a quem fica a cargo resolver os casos entre os indios. (BRASIL, 1955, grifos nossos).

É importante destacar que desde muito cedo, período em que as reservas indígenas ainda não enfrentavam a superpopulação observada no século XXI, os processos de escolha e aceitação de capitães já eram conflituosos. O antropólogo Eduardo Galvão (1996) relata em seu caderno de campo uma situação ocorrida em novembro de 1943, na Reserva Indígena Taqueperi, que então tinha uma população de 175 pessoas. Galvão trouxe a lume o caso ocorrido em um sábado no qual os indígenas e o chefe do Posto foram até a cidade para comprar alguns gêneros, dentre eles aguardente. Na divisão dos itens comprados surgiu uma grande confusão, pois, segundo o relato, o capitão "[...] encarregado de fazer a distribuição, tanto do sal e sabão, como da pinga, guardou a maior parte para si. Disto, ao que parece, resultou a briga [...]" (GALVÃO, 1996, p. 210).

A briga foi violenta, resultando inclusive em feridos. Parte dos indígenas não aceitava mais Cândido como capitão e diante da crise e até mesmo para se preservar este se retirou da reserva. Quando os fatos ocorreram o chefe do Posto não estava na reserva, coube aos antropólogos presentes, dentre eles Galvão, indicar um substituto temporário para o capitão. Porém, com a chegada de Dayen, o chefe do Posto, o nome indicado por rejeitado.

Dayen chegou hoje. Sua chegada deveria resolver a questão da indicação do capitão. Dayen não aceitou Venâncio, por nós indicado, provisoriamente, no cargo. Dayen o considera demasiado "safado" e "turbulento" para o cargo. Acredita que Aparício, Justino, Risquim e Venâncio estão no mesmo nível. Para ele, Cândido seria melhor, porém fizemos por impor a nossa vontade. Cândido é realmente mal querido, partindo na preferência para capitão, 
por parte de Alberto, por alguma razão que ainda não descobrimos qual. A razão alegada tem sido sempre a de que "ele fez esse povo produzir com Venâncio ou qualquer outro, ficariam eternamente a vagabundear e a passar os dias cantando à Ñandejara". Cândido acabou com esse estado de coisas. Sua função não era, ao que nos parece, a de capitão, mas, sim, a de capataz. (GALVÃO, 1996, p. 211, grifos nossos).

As considerações de Galvão apontam para o perfil esperado do capitão. Para o agente do SPI, o capitão deveria impor os padrões de organização do trabalho capitalista rural. Era alguém que devia estar disposto a obedecer às determinações do órgão indigenista, não ser "turbulento" diante das ordens do chefe de Posto. Esperava-se que os indígenas abandonassem suas práticas tradicionais e se dedicassem à produção agrícola de forma intensiva, deixando de lado aquilo que não era do mundo "civilizado" ou do mundo do "mercado".

O capitão devia exercer seu poder com base na coerção para impor o projeto civilizatório do Estado. Todavia, existia um ponto limite nessa organização, pois para que tivesse êxito o capitão precisava manter um bom nível de aceitação dentro da comunidade. Cândido não conseguiu isso. Não conseguiu porque não dividiu os recursos a contento nem mesmo com seus parentes. Já em 1943, Galvão via problemas nessa forma de governo. "Nossa impressão tem sido a de que o capitão tem realmente alguma autoridade, principalmente no que se refere ao trabalho conjunto. É, no entanto, uma autoridade dada pelo SPI, parecendo que já se encontra mais estratificada aqui, que no norte" (GALVÃO, 1996, p. 210-1, grifos nossos).

Mesmo na contemporaneidade, após a Constituição de 1988 que formalmente derrubou o poder tutelar, as questões relacionadas à capitania seguem gerando contendas. Citamos, por exemplo, as disputas violentas ocorridas em nas Terras Indígenas Limão Verde (2005) e Porto Lindo (2006), casos analisados por Tonico Benites (2009). Este autor também tece considerações sobre dois temas relevantes associados à violência. O primeiro se refere à prática de atos de violência pelo Capitão. (Corolário da necessária utilização da força para promoção da obediência) (BARNES, 1960). O segundo, corolário, deste é a utilização de "fofocas" para mediante agressões fictícias (ou mesmo reais) reclamar perante os órgãos estatais para a troca do capitão (com a provável assunção de grupo ligado ao denunciante). 
Ele pode também estabelecer uma aliança com políticos municipais, estaduais e federais. Além disso, o capitão atualmente tem acesso direto ao organismo civil, militar e federal, contando com a força policial para manter a "ordem" nas aldeias. Assim ele se sobrepõe aos seus adversários políticos.

Diante disto. as famílias não representadas pelo capitão, às vezes fazem manifestações e fofocas contra ele, pedem com freqüência por meio de documentos escritos a sua exoneração e reivindicam aos agentes indigenistas novas eleições. As famílias adversárias fazem também manifestações em grupo contra os atos de violência e prisões comandadas pelos capitães. (BENITES, 2009, p. 90).

Na linha traçada por Malinowski (1945, p. 147), a imposição da indirect rule visava promover uma "[...] uma liderança local devotada, dependente, controlada, mas poderosa, rica e satisfeita". Ferreira (2007) analisando o caso da Terra Indígena Cachoeirinha, ocupada pelos Terena, aponta para as estruturas socioeconômicas de poder associadas à figura do capitão na contemporaneidade. Embora a pesquisa citada se refira aos Terena, é possível associar ao caso que estamos analisando, pois o padrão de atuação do SPI e de sua sucessora a Fundação Nacional do Índio (FUNAI) se estendia por todo o país, em especial pelo sul do antigo Mato Grosso.

A autoridade formal do Cacique pode ser classificada em três áreas de incidência: 1) as relações pessoais e familiares dentro da aldeia. Quer dizer, o poder do cacique é uma forma de controle sobre as atividades dos indivíduos com relação especialmente ao uso de bebidas alcoólicas, fixação de residência (quando indígenas vêem de fora, de outra aldeia) e conduta "criminal" dos indivíduos, se eles cumprem ou não a lei; 2) as relações interétnicas, é uma forma de controle das relações entre os membros do grupo com indivíduos e grupos não indígenas ou outros grupos étnicos, implicando controle do acesso (entrada/saída) da área indígena e ao poder de representação formal do grupo perante as instituições e grupos sociais; 3) é uma forma de controle das relações econômicas e bens "coletivos" do grupo, que dizem respeito ao controle exercido pelo Cacique sobre os contratos de trabalho assinados pelos índios com empresas, atualmente, com as Usinas de Cana de Açúcar, sobre os veículos (trator, caminhonetes, caminhões) que porventura existam, e também os armazéns e recursos e implementos agrícolas que o grupo receba, seja do Governo Federal, seja do Governo Estadual ou Municipal, ou ainda, por meio de projetos de organizações não governamentais. (FERREIRA, 2007, p. 268, grifos nossos).

Tonico Benites (2009) apresenta elementos da mesma natureza ao expor a importância do controle de recursos associados ao exercício da capitania. 0 
capitão não tem apenas poder político e de coerção, mas também poder econômico associado, pois em grande parte dos momentos gerencia recursos externos destinados à comunidade.

Cabe salientar que o reconhecimento do capitão pelos órgãos públicos é, no entendimento das famílias Kaiowá, um cargo que oferece muitas vantagens advindas de diversas fontes. Como o recebimento de taxa comunitária da usina de álcool (ao liberar os homens para trabalho). O capitão igualmente tem mais poder para indicar integrantes de sua família para cargos assalariados - professor, agente de saúde. (BENITES, 2009, p. 93-4).

Há pouco tempo a FUNAI deixou, ao menos oficialmente, de interferir na escolha de capitães. O telex n. 94, de 9 outubro de 1990 orientou os servidores da fundação a pararem de interferir na não mais interferir na escolha de capitães (BRAND, 2004, p. 233). Ainda mais recente, data de 15 de maio de 2008 a Portaria n. 491 do presidente da FUNAI, ela versa principalmente sobre segurança pública em terras indígenas. Tal portaria pode ser considerada como a proibição definitiva da interferência da FUNAI na escolha dos capitães (CAVALCANTE, 2013, p. 149).

Segundo ela:

Art. 10 A AER Cone Sul deve dar publicidade ao fato de que a liderança indígena denominada "Capitão" goza da mesma autoridade que outras lideranças, sendo que todas as lideranças gozam da mesma legitimidade junto às comunidades. Esse relevante detalhe deve ser enfatizado, não apenas aos agentes de segurança, mas também a todo e qualquer agente público e privado que atue em terras indígenas.

Parágrafo único. Deve-se dar publicidade ao fato de que a FUNAI não emite qualquer documento reconhecendo lideranças ou capitães. As antigas carteirinhas plastificadas denominadas de "Portaria de Capitão" não gozam de efeito legal. (BRASIL, 2008, grifos nossos).

O acesso aos recursos e a consequente deslocação dos interesses na nomeação dos capitães dos chefes de Posto para as lideranças políticas locais (municipais e estaduais, em face do número de eleitores) acarreta a perpetuação da presença colonial e da consequente intervenção do órgão indigenista. Isso se confirma quando se observa o chamamento, ou a quase imposição pelos indígenas, de mediação pela FUNAI no processo de escolha do capitão. 
Os resquícios do papel que o órgão indigenista oficial exerceu como definidor de lideranças têm sido constantemente observados em minha prática indigenista. Desde que ingressei no órgão indigenista, frequentemente participo de mediações de conflitos entre lideranças indígenas. Nessas ocasiões, percebo que as lideranças esperam que atuemos como uma espécie de juiz, que digamos quem está certo e, portanto, quem tem legitimidade para exercer a liderança em determinada aldeia. Quando Ihes digo que a FUNAI não exerce mais o papel de definidor de lideranças e que estamos ali apenas para acompanhar o processo interno de negociações, são notáveis as reações de descontentamento. São frequentes, inclusive, as exclamações do tipo "hoje o doutor tem que resolver isso, se não ninguém sai daqui". (CAVALCANTE, 2013, p. 150).

Percebe-se que o modelo de governo indireto imposto pelo SPI, apesar da superação formal do poder tutelar, permanece vigente na visão de muitos agentes públicos e, em boa medida, dos próprios indígenas. A Constituição de 1988 formalmente eliminou o paradigma assimilacionista como condutor da política indígenas nacional, mas a mudança constitucional não implicou em imediatas mudanças práticas. As transformações nas relações entre o Estado e povos indígenas se darão lentamente por meio de um processo de reconstrução de autonomias que nem sempre é bem acolhido por todos os agentes envolvidos.

\section{CONSIDERAÇÕES FINAIS}

O órgão indigenista estatal, com a visão homogeneizadora do "índio genérico" estabeleceu uma estrutura hierarquizada com critérios externos de escolha de lideranças a povos que se organizavam de forma diversa, como no caso dos Ava-Guarani e Ava-Kaiowá. Como exposto por Brand, os Ava-Guarani e Ava-Kaiowá foram duplamente prejudicados "[...] Na transferência para dentro das reservas, não se trata apenas de aceitar lideranças mais jovens, eleitas a partir de novos parâmetros de legitimidade, mas de aceitar a liderança de alguém que, em muitos casos, nem sequer integrava a sua aldeia. [...]" (BRAND, 1993, p. 72). Oliveira (1986, p. 376) agrega que "[...] a administração ignora as concepções nativas sobre o poder e autoridade, imaginando o cargo de capitão com um último patamar da hierarquia colonial, desempenhando assim um papel determinante na escolha [...]".

O processo externo de escolha, fundamentada no índio genérico, não resistiu às diferenças entre os povos indígenas. O documento do SPI, citado a seguir, 
relata a utilização da Polícia Indígena do Posto Indígena, composta por indígenas Kaiowá para efetuação da prisão de um Terena. O chefe de posto relata que "[...]

\section{estes são Caiuás, e eles Terena, existindo uma certa rivalidade entre as raças} [...] mandei uma escolta composta de três homens [...] este levava uma carabina". Houve resistência e agressões verbais denotativas da tensão inter-étnica "[...] este já sabia de facão em punho dizendo que não se entregava para esses índios sujos e que ele iria mostrar como ele era homem [...]". Como resultado a polícia disparou na perna do "infrator" "[...] um segundo tiro, que atingiu na perna direita, quebrando na altura da cocha (sic)" (BRASIL, 1949, grifos nossos).

O indirect rule imposto pelo SPI aos indígenas modificou as formas de organização social vivenciadas em um novo ambiente de territorialização, a reserva. Antes do reservamento, os Kaiowá e os Guarani se organizavam em grupos familiares ou estavam unidos por laços políticos sólidos. Eram liderados pelos chefes de famílias extensas (tuvicha ou tamõi) e de tekoha (tuvicha ruvicha). Tal liderança era em geral um avô respeitado pela parentela. Ele era, sobretudo, um construtor de consensos, um aconselhador e um distribuidor de dons. A capitania impõe a figura do líder coercitivo, figura associada ao Estado para a imposição do projeto "civilizacional", cria-se uma forte concorrência com relação aos líderes tradicionais, especialmente devido ao poder econômico e coercitivo atribuído ao capitão.

Malgrado a intervenção tutelar no processo de seleção do capitão, de certa forma houve a apropriação, especialmente na Reserva Indígena de Dourados, da sua figura enquanto modelo de liderança. Desconsiderar que houve a sua ressignificação pela comunidade indígena é tornar a replicar argumentos eurocêntricos que negam esta capacidade a culturas consideradas "inferiores". Obviamente, o histórico de acesso a recursos econômicos (privados e públicos) e humanos desempenha relevante peso nesta equação. O desfazimento dos efeitos da instituição da liderança local devotada, dependente, controlada mas poderosa, rica e satisfeita não é tão simples, especialmente porque novos atores rivalizam pelo acesso privilegiado aos capitães: missionários, ONG's, prefeitos, vereadores, deputados, lideranças rurais, empresários, especialmente de ramos de utilização intensiva de mão de obra como, por exemplo, frigoríficos. Não é possível estabelecer acriticamente a clivagem entre "tradicional" e "colonizado". A negação da possibilidade da mudança e, especialmente, da legitimidade expõe mais uma assunção eurocêntrica, na direção errada. Ou como exposto por Fabian, negamos 
a pertença ao mesmo tempo ao "nativo", ao "selvagem". Temos a "[...] persistent and systematic tendency to place the referent(s) of anthropology in a Time other than the present of the producer of anthropological discourse[...]"5 (FABIAN, 2002, p. 31). Como corolário desta afirmação, eventuais novas intervenções destinadas a empoderar as lideranças das famílias extensas em desapreço ao capitão, escolhido pela comunidade, correm o risco de reproduzir os mesmos resultados nefastos das interferências coloniais que tentam, supostamente, corrigir.

\section{REFERÊNCIAS}

BARBOSA, G. P. Relatório da Inspectoria de Matto Grosso, Serviço de Proteção aos Índios, 1927. In: MONTEIRO, M. E. B. Levantamento histórico sobre os índios Guarani Kaiwá. Rio de Janeiro: Museu do Índio, 2003.

BARNES, J. A. Indigenous politics and colonial administration with special reference to Australia. Comparative Studies in Society and History, v. 2, n. 2, p. 133-49, jan. 1960,

BENITES, T. A escola na ótica dos Ava Kaiowá: impactos e interpretações indígenas. Orientador: João Pacheco de Oliveira. 2009. 106 fl. Dissertação (Mestrado em Antropologia Social) - Museu Nacional, Universidade Federal do Rio de Janeiro, Rio de Janeiro, 2009.

BLANCHETT, T. La antropología aplicada y la administración indígena en los Estados Unidos: 1934-1945. Desacatos, n. 33, p. 33-52, maio/ago. 2010.

BRAND, Antonio Jacó. O confinamento e o seu impacto sobre os Pai-Kaiowá. 1993. Dissertação (Mestrado em História) - Pontifícia Universidade Católica do Rio Grande do Sul, Porto Alegre, 1993.

BRAND, A. O bom mesmo é ficar sem capitão: o problema da "administração" das reservas indígenas Kaiowá/Guarani, MS. Tellus, Campo Grande, v. 1, n. 1, p. 67-88, out. 2001.

BRAND, A. Os complexos caminhos da luta pela terra entre os Kaiowá e Guarani no MS. Tellus, Campo Grande, v. 4, n. 6, p. 137-50, abr. 2004.

BRASIL. Portaria n. 491/PRES, de 15 de maio de 2008. Disponível em: http:// www.funai.gov.br/arquivos/conteudo/cogedi/pdf/Boletim\%20de\%20Servicos/2008/ Separata\%2009-11\%20de\%2006.06.08.pdf. Acesso em: 7 ago. 2018.

5 " [...] uma persistente e sistemática tendência de colocar os integrantes da cultura estudada em um tempo diferente que o presente do responsável pelo discurso antropológico[...]” Tradução nossa. 
BRASIL. Decreto-Lei n. 1.736, de 3 de novembro de 1939. Subordina ao Ministério da Agricultura o Serviço de Proteção ao Índio. Disponível em: http://www2.camara. leg.br/legin/fed/declei/1930-1939/decreto-lei-1736-3-novembro-1939-411705publicacaooriginal-1-pe.html. Acesso em: 7 ago. 2018.

BRASIL. Serviço de Proteção ao Índio. Relatório de Diretoria de 1917. Arquivo do SPI, microfilme 380, f. 1239. Rio de Janeiro: Museu do Índio, 1917.

BRASIL. Serviço de Proteção ao Índio. Memorando n. 706, de 22 de novembro de 1955, de Deocleciano de Souza Nenê, chefe da 5 a Inspetoria Regional do SPI, para o encarregado do Posto Indígena Francisco Horta. In: BRASIL. Ministério Público Federal (MPF). Microfilme n. 006_01406. Cópia digital de microfilmes do Museu do Índio - Rio de Janeiro-RJ. Arquivo da Procuradoria da República no Município de Dourados, MS, [s.d.].

BRASIL. Serviço de Proteção ao Índio. Memorando n. 119, de 19 de fevereiro de 1954, de Deocleciano de Souza Nenê, chefe da 5a Inspetoria Regional do SPI, para o encarregado do Posto Indígena José de Bonifácio. Disponível em: http://www.docvirt.com/docreader. net/DocReader.aspx?bib=mi_arquivistico\&pagfis=104373. Acesso em: 7 ago. 2018.

BRASIL. Serviço de Proteção ao Índio. Ofício n. 16, de 28 de abril de 1949, do agente do Posto Indígena Francisco Horta para Joaquim Fausto Prado, chefe da Inspetoria Regional do SPI. In: BRASIL. Ministério Público Federal (MPF). Microfilme n. 006_02125. Cópia digital de microfilmes do Museu do Índio - Rio de Janeiro, RJ. Arquivo da Procuradoria da República no Município de Dourados, MS, [s.d.].

BRASIL. Ministério de Agricultura Indústria e Comércio. Relatório do Ministério de Agricultura Indústria e Comércio de 1913. In: LIMA, Antonio Carlos de Souza. Um grande cerco de paz - poder tutelar, indianidade e formação do estado no Brasil. Petrópolis: Vozes, 1995. $130 \mathrm{p}$.

BRASIL. Ministério de Agricultura Indústria e Comércio. Relatório do Ministério de Agricultura Indústria e Comércio de 1917. In: LIMA, Antonio Carlos de Souza. Um grande cerco de paz. Poder Tutelar, Indianidade e Formação do Estado no Brasil. Petrópolis: Vozes, 1995. p. 119.

CASANOVA, Pablo González. Colonialismo Interno. In: BORON, A. A.; AMADEO,J.; GONZÁLEZ, S. (Org.). A teoría marxista hoje: problemas e perspectivas. Buenos Aires: CLACSO; São Paulo: Expressão Popular, 2006. p. 395-420.

CAVALCANTE, T. L. V. Colonialismo, território e territorialidade: a luta pela terra dos Guarani e Kaiowa em Mato Grosso do Sul. Orientadora: Lúcia Helena Oliveira Silva. 2013. Tese (Doutorado em História)- Universidade Estadual Paulista, Assis, SP, 2013. 
FABIAN, Johannes. Time and Other. How Anthropology makes its object. New York: Columbia University Press, 2002.

FERREIRA, Andrey Cordeiro. Tutela e Resistência Indígena: etnografia e história das relações de poder entre os Terena e o Estado brasileiro. 2007. Tese (Doutorado em Antropologia Social) - Programa de Pós-Graduação em Antropologia Social, Museu Nacional, Universidade Federal do Rio de Janeiro, Rio de Janeiro, 2007.

GALVÃO, Eduardo. Diários de Campo entre os Tenetehara, Kaioá e Índios do Xingu. Rio de Janeiro: Editora UFRJ; Museu do Índio-FUNAI, 1996.

LECLERC, G. Crítica da Antropologia - Ensaio acerca da história do africanismo. Lisboa: Estampa, 1973.

LIMA, A. C. S. Um grande cerco de paz. Poder tutelar, indianidade e formação do estado no Brasil. Petrópolis: Vozes, 1995.

LIMA, A. C. S. Sobre indigenismo, autoritarismo e nacionalidade: considerações sobre a constituição do discurso e da prática da proteção fraternal no Brasil. In: OLIVEIRA FILHO, J. P. (Ed.). Sociedades indígenas e indigenismo no Brasil. Rio de Janeiro: EdUFRJ; São Paulo: Marco Zero, 1987.

LUGARD, F. D. The dual mandate in British tropical Africa. Londres: W. Blackwood, 1929.

MAGALHÃES, C. O selvagem. Rio de Janeiro: Typographia da Reforma, 1876. Disponível em: cdpb.org.br. Acesso em: 30 set. 2014

MALINOWSKI, Bronislaw. Indirect rule and its scientific planning. In: KABERRY, P. M. (Org.). The dynamics of culture change: an inquiry into race relations in Africa. New Haven: Yale University Press, 1945, p. 138-50.

MAMDANI, M. Citizen and subject: contemporary Africa and the legacy of late colonialism. Princeton: Princeton University Press, 1996.

NIMUENDAJU Unkel, Curt. As lendas da criação e destruição do mundo como fundamento da religião dos Apapnocuva Guarani. São Paulo: Hucitec/USP, 1987.

OLIVEIRA FILHO, J. P. O nosso governo: os Ticuna e o regime tutelar. 1986. Tese (Doutorado em Antropologia) - Museu Nacional, Universidade Federal do Rio de Janeiro, Rio de Janeiro, 1986.

PESSOA, F. Fiç̧ão e teatro. Portugal: Europa-América, 1986. 
SILVA, Alexandra Barbosa da. Mais além da "aldeia": território e redes sociais entre os Guarani de Mato Grosso do Sul. 2007. Tese (Doutorado em Antropologia Social)- Museu Nacional, Universidade Federal do Rio de Janeiro, Rio de Janeiro.

QUIJANO, A. Colonialidade do poder, eurocentrismo e América Latina. In: LANDER, E. (Org.). A colonialidade do saber: eurocentrismo e ciências sociais. Perspectivas latinoamericanas. Buenos Aires: CLACSO, 2005.

SUSNIK, B. Los aborigenes del Paraguay II. Etnohistoria de los Guaranies. Epoca colonial. Asuncion: Museo Etnografico "Andres Barbero", 1979-1980.

\section{Sobre os autores:}

Marco Antonio Delfino de Almeida - Doutorando em História e mestre em Antropologia pela Universidade Federal da Grande Dourados (UFGD). Graduado em Direito pelo Centro Universitário Anhanguera de Campo Grande (UNAES). Procurador da República do Ministério Público Federal (MPF) de Dourados, MS. E-mail:marcodalmeida@gmail.com

Thiago Leandro Vieira Cavalcante - Doutor em História pela Universidade Estadual Paulista "Júlio de Mesquita Filho" (UNESP/Assis). Mestre em História pela Universidade Federal da Grande Dourados (UFGD). Graduado em História pela Universidade Estadual de Londrina (UEL). Professor do curso de História e do Programa de Pós-Graduação em História da Universidade Federal da Grande Dourados. Atualmente desenvolve estágio de pós-doutorado na Universidade Estadual de Maringá. E-mail: thiago_cavalcante@hotmail.com

Recebido em 13 de agosto de 2018

Aprovado para publicação em 22 de novembro de 2018 